\title{
CLUNY E A FEUDO-CLERICALIZAÇÃo DE CASTELA
}

\author{
Hilário Franco Junior *
}

O mosteiro de Cluny, fundado em 909, na Borgonha, pelo duque Guilherme da Aquitânia, desde suas origens, esteve fortemente vinculado à sociedade feudal, ou feudo-clerical como preferimos denominar, ainda que este não seja o local para justificar a expressð̃o. ${ }^{1}$ Declaradamente, o espírito de sua fundação era fazer com que os monges "nunca se submetam ao jugo de qualquer poder terreno" 2 Para tanto, Cluny estava isenta da jurisdição episcopal, ligando-se diretamente a Santa Se, encontrando-se in jure et proprietate beati Petri. Contudo, a origem nobiliárquica de seus membros $\mathrm{e}$ as doações fundiárias recebidas inseriram a abadia na economia senhorial e nas relaçбes feudo-vassálicas.

Assim, Cluny não podia deixar de expressar o expansionismo tŕpico daquela sociedade agrária e crista. Ou seja, de uma organização econômica que, pela pobreza da tecnologia agrícola utilizada, revelava-se uma grande devoradora de terras. De um espírito religioso catequizador, universalisante - "ide, fazei apóstolos de todas as naçoes, batizando-os" (Mt 28,19) que pretendia se impor aos pagaos, fosse pela palavra, fosse pela espada. Aliás, "a espada do espírito é a palavra de Deus" (Ef 6,17) daí a relação estrutural dos dois conceitos para aquela sociedade, o que ficou etimologicamente registrado na língua inglesa através dos termos gêmeos word e sword.

A própria organizaçao da Ordem Cluniacense refletia seu espírito feudo-clerical. De fato, todos os mosteiros encontravam-se estreitamente ligados a abadia central, adotando integralmente sua regra, pagando-lhe uma pequena constribuição anual, e ainda com os monges prestando um juramento de fidelidade ao abade de Cluny. Entre as inúmeras casas da Ordem havia um rígida hierarquia, que tinha no seu cume a abadia-mãe, por sua vez submetida à Santa Sé, como que numa extensa cadeia de vassalagem lígia. Nðo havia relaçбes horizontais, entre unidades de igual categoria, reportando-se todas ao nf́vel hierárquico superior. A isenção 
em relação ao poder local dos bispos fazia de cada um de seus mosteiros encraves nas respectivas dioceses, coerentemente com o espírito feudal, da mesma forma que cada castelao escapava à autoridade real ou condal.

Desta maneira, o caráter expansionista, presente desde os primeiros tempos, levou a Ordem, quando de seu apogeu, em fins do século XI e princípios do XII, a reunir 1184 mosteiros, dos quais apenas 31 na Península Ibérica ${ }^{3}$ No entanto, é preciso lembrar que naquele momento o território peninsular em maos cristas era ainda reduzido, e que Cluny apenas iniciou o processo de feudo-clericalizaçao ibérico, completado pelos mosteiros de Cister, pelas peregrinaçбes a Compostela e pela decisiva participaçao transpirenaica na Reconquista. De qualquer maneira, a presença da Ordem Cluniacense, na Hispânia, respondia a dois importantes fenômenos da época, a Reforma Gregoriana e a expansão demográfica, trabalhando como um instrumento de fortalecimento do Papado e de largamento da Cristandade. E, conseqüentemente, como instrumento de feudo-clericalizaçao do norte peninsular.

Para a teocracia papal em formaçao, na qual significativamente destacaram-se pontífices cluniacenses, implantar o rito romano, ou mais propriamente galicano-romano, na Ibéria, era tarefa justa e necessária. Símbolo não só da preeminência da Sé Apostólica de Roma, mas também da unidade crista - cuja melhor formulaçao encontra-se em Gregório VII: "a Igreja romana foi fundada unicamente por Deus; aquilo que ño esteja em conformidade com a Igreja romana não pode ser tido por católico"4

o rito romano vinha já há tempos suplantando as liturgias locais, resquícios da época bárbara. Contudo, a Igreja peninsular, isolada pela invasđo muçulmana, mantivera o rito da época visigótica, chamado algo impropriamente de moçárabe. Ele implicava em diferenças teológicas discutíveis, dar desde o século VIII ter sido muitas vezes visto com suspeitas de heresia. ${ }^{5}$

Contudo, legados papais, enviados à península nas primeiras décadas do século X e mesmo no pontificado de Alexandre II (1061-1073), concluíram pela ortodoxia da liturgia hispânica, o que poderia ter encerrado teologicamente a questao, nđo fosse o caráter teocrático e unitarista da Reforma Gregoriana. Isto fica muito claro através de uma carta de Gregório VII aos reis Afonso VI de Leão e Sancho II de Castela, onde afirma que "como bons filhos, apesar de uma longa separação, reconheçais enfim a Igreja romana como vossa verdadeira mae, e assim vereis que somos vosso irmão. (. . ) Seguindo o exemplo dos outros reinos do ocidente e do norte, aceitem a disciplina e o ritual romanos, nao os de Toledo nem de nenhuma outra que não seja a Igreja que foi fundada por Pedro e Paulo" 6 $\mathrm{Na}$ verdade, a diferença mais marcante entre os dois ritos era o fato da 
hóstia ser dividida em nove partes na liturgia visıgoda e em três na romana. Portanto, o que estava em jogo nao era a espiritualidade - essencialmente a mesma nos dois lados dos Pirineus - mas uma disputa pela preeminência entre o Papado e a Igreja Espanhola.

Como essa última era muito ciosa de sua autonomia, nascida do isolamento provocado pela presença islâmica, resistia às pressớs de Roma, interessada nas novas dioceses formadas com os primeiros sucessos da Reconquista. Daí Afonso VI, após a aceitação da liturgia papal, ter escrito ao abade Hugo de Cluny "saiba que por causa do rito romano que por ordem tua recebemos, nosso reino está em completa desolação". ${ }^{7}$ De fato, para cimentar sua ligaç̃o com Cluny e o Papado, Afonso VI desconsiderara o resultado do duelo judiciário entre os representantes dos dois ritos, ocorrido em Burgos nos primeiros meses de 1077, que terminara com a vitória do representante hispânico ${ }^{8}$ Desde entao, como observa Sánchez Albornos, ño sem um certo exagero nacionalista, o Papado se constitui em força decisiva na vida peninsular, submete a "igreja nacional da monarquia", provoca grave sangria de riqueza, saindo "rios de ouro e prata" da Espanha, em suma "reverência" obediência e devoção ante o Vigário de Cristo".?

A partir de entao, a presença de Cluny, na Península Ibérica, enquanto elemento de ampliação da área da sociedade feudo-clerical, abrindo novas possibilidades para a nobreza transpirenaica que via seus quadros alargados pelo crescimento populacional da época, deu-se de quatro formas. A primeira através de doaçðes em bens de raiz recebidas por seus mosteiros de reis e de particulares, o que representava uma crescente riqueza que atrafa $\mid$ mais e mais indivíduos de além-Pirineus para as casas peninsulares ligadas a ordem. Sobretudo importantes eram as doações reais, expressão da mentalidade perdulária que levava, em todo Ocidente Medieval, os monarcas a entregarem inúmeros bens aos monges em troca da in tercessão deles diante do Divino. ${ }^{10}$ No caso ibérico isso ocorreu especialmente com os reis-imperadores de Leão, Fernando I (1038-1065) e Afonso VI (1072-1109), principais responsáveis na península pelo progresso material da Ordem, a quem pediam orações e ofícios litúrgicos a favor do reino e de seus soberanos. ${ }^{11}$ Sem entrarmos na longa discussão sobre o tipo de elo estabelecido entre cada mosteiro ibérico e Cluny (laços jurídicos, filiaçao fundacional, observância da regra), o que é pouco importante para nossos objetivos, exemplifiquemos com um caso de Castela, outro de Leão e outro das Astúrias.

A abadia de Silos recebeu no século XI, a partir do iń́cio da década de 1040, quando sofre a influência cluniacense, 10 doaçбes, das quais 
apenas uma ño em bens imóveis, ${ }^{12}$ e 21 no século seguinte, todas em bens de raiz. ${ }^{13}$ Ou seja, naquele período, Silos recebeu em média uma doação imobiliária a cada pouco mais de cinco anos. O caso de Eslonza é mais claro: 16 no século XI, ${ }^{14} 32$ no século $\mathrm{XII},{ }^{15}$ isto é, se considerarmos que o mosteiro recebeu a reforma cluniacense apenas por volta de 1090 (com 6 doaçōes nesta década), concluiremos que, em média, ele recebeu na fase cluniacense uma doação a cada quase três anos. $\mathrm{O}$ velho mosteiro de San Vicente de Oviedo, por sua vez, tornou-se beneditino em meados do século $\mathrm{XI}$, recebendo desde então, até o final da centúria, 21 doaçðes, média de uma a cada dois anos, ${ }^{16}$ e durante o século XII, 91, portanto, perto de uma doaçao por ano. ${ }^{17}$

Logo, diferenças significativas no ritmo de crescimento fundiário daqueles mosteiros, fenômeno cuja explicação, no entanto, talvez esteja mais ao nível da documentaçao do que dos fatos. Realmente, há uma sensível desproporção na massa documental que chegou até nós: Eslonza com 197 cartas até fins do século XIII, Silos com 292 e Oviedo com 369 até fins do século XII apenas. Poder-se-ia objetar que o maior volume de doaçбes no século XII resultava das melhores condiçбes econômicas da época e não do poder de atração de Cluny. Mas isso seria esquecer que o crescimento econômico de entao decorria da própria dinâmica feudoclerical, e, assim, em certa parte, de Cluny. De qualquer forma, e é isso que nos importa, ño se pode negar que crescentes extensठ̃es de terras peninsulares eram integradas, via Cluny, à órbita feudo-clerical.

Muito ilustrativo nesse sentido é o caso de Santo Toríbio de Liébana, que em 1183 foi transferido para um dos mais importantes mosteiros cluniacenses ibéricos, San Salvador de Ona. Desde sua fundaçao no século IX, Liébana recebera 34 doaçбes, depois de passar para Ona, até fins do século XIII, recebeu 29. Portanto, na fase pré-cluniacense em média uma a cada sete anos e meio, ${ }^{18}$ depois uma a cada quatro anos. ${ }^{19}$ Expressando melhor a intensidade desse enriquecimento, lembremos que ele ocorreu em grande parte no século XIII, quando o monastıcismo cluniacense ibérico já ultrapassara sua fase áurea, e a integraçao de terras ao FeudoClericalismo se fazia por outros canais. Mesmo no século XIII, quando aquele papel de Cluny como intensa agregadora de áreas à sociedade feudoclerical estava bem reduzido, a própria abadia borgonhesa, e nao apenas um mosteiro filiado, recebeu terras de Afonso IX e Fernando III substituindo um censo que lhe era pago anteriormente em moeda. ${ }^{20}$

A segunda forma através da qual Cluny desempenhou aquele papel de arrete da expansão feudo-clerical foi como produtora ideológica. Reunindo e sintetizando os interesses teocráticos do Papado e as necessidades da aristocracia fundiária, e naturalmente elaborando tudo isso de acordo 
com a mentalidade da época, Cluny propagou as idéias de um belicismo feudo-clerical que atendia perfeitamente aquelas condiçбes. Mas o caráter inovador daquela proposta chocava os espíritos conservadores, o que levou um bispo do século $\mathrm{XI}$, desgostoso com o crescente prestígio monástico, que escapava à sua jurisdiç̧o, a criticar aquela novidade da "ordem belicosa dos monges". ${ }^{21}$ Formulaçao nova, que levava um deles a se dizer "cavaleiro permanecendo monge", e a orgulhosamente afirmar ter lutado no sul frânces contra os sarracenos com tal zelo que "nem sei mais quantos abati com minhas maos". ${ }^{22}$ Contudo, numa reaçao a um certo momento historiográfico que hipervalorizou Cluny, considerando-a responsável por todos os acontecimentos do período, já se tentou negar a participaçáo cluniacense na formaçao da idéia de guerra santa. A argumentaçao baseiase no fato de que a Filosofia de História das Cruzadas é incompatível com as concepçбes que se encontram nos escritos de Odilon de Cluny (962-1048), estando a abadia borgonhesa ligada à Igreja da Paz de Deus, portanto, mais à concepção carolíngia e otoniana que à gregoriana. ${ }^{23}$

Apesar de enunciadas por um especialista, estas consideraçбes nđo são sustentåveis, pois desconsideram alguns aspectos fundamentais da questao. Em primeiro lugar, não se pode reduzir o pensamento cluniacense somente à pena de Odilon, sobretudo quando contemporâneos seus, como por exemplo Ricardo de Saint Vitor, tinham posição diferente. Depois, como o próprio autor reconhece, Cluny sem dúvida contribuiu para a concepção do miles cristão, daqueles que colocavam a espada a serviço da Igreja, prova de que se aceitava e, mais ainda, se exaltava a atividade bélica dirigida para aquele fim, vista então como santificada. Sobretudo não e possível se deixar iludir pela aparente contradição entre Paz de Deus e Guerra Santa, na verdade, conceitos complementares, que impunham uma concepção de mundo estabilizadora internamente e expansionista externamente, o que atendia aos interesses das elites, sobretudo da monástica, criadora daquele modelo ideológico.

Como já se observou há mais tempo, e com mais razão, "Cluny não lança um programa, |ño traça planos de campanha, os quais não estão absolutamente nos seus hábitos, mas cria e alimenta uma atmosfera, um espirito". ${ }^{24}$ E neste sentido que se deve entender a participaçåo de Cluny no famoso episódio do ataque à fortaleza muçulmana de Barbastro, ocorrido em 1064-1065 e que já contava com a participaçå de franceses. E verdade que não se deve, para aquele momento, considerar o papel de Cluny e do Papado decisivos, como já se fez. ${ }^{25}$ Cluny encontrava-se então afastada de Aragão devido ds suas estreitas relaçðes com Castela-Leão, e Alexandre II via-se envolvido na disputa com um anti-papa. Contudo, o pontífice não deixou de conceder remissão dos pecados a quem participasse da luta 
anti-mulçumana na Espanha, ${ }^{26}$ e pensava mesmo numa expedição militar que tinha todas as características essenciais de cruzada. ${ }^{27}$ Mas ainda, se o abade seguinte, Hugo de Cluny, parece não ter incentivado as Cruzadas no Oriente, foi justamente por que as da Espanha se lhe afiguravam mais interessantes. ${ }^{28}$

Bem de acordo com essa concepçao, duas fontes cluniacenses falam dos mortos em combate contra os islamitas peninsulares como sendo mártires. ${ }^{29} \hat{E}$ verdade que aquelas concepçðes ño eram inteiramente novas e muito menos exclusivamente cluniacenses, mas elas foram ampliadas e sistematizadas num momento e com um espírito cujos tons denotam claramente a pesença de Cluny. O ponto de vista gregoriano, e portanto cluniacense, transparece mitidamente, e, na sua forma "oficializada", em meados século XII: "o reino dos céus é outorgado por Deus a quem morre em defesa dos cristaos", ${ }^{30}$ ou ainda "os hereges devem ser induzidos a aceitar a salvação mesmo contra a sua vontade". ${ }^{11} \mathrm{Da}$ mesma forma que o arcebispo Turpin lutara contra pagaos na Dinamarca e infiéis na Espanha, ${ }^{32}$ na península, o bispo Jerônimo, de origem francesa, nđo só absolvia antecipadamente os combatentes como pedia ao Cid o privilégio de começar a batalha. ${ }^{33}$ Do entrecruzar da religiosidade popular, que já trazia em si elementos feudais e belicistas, com o espírito cruzadístico de Cluny, resultante da anterior e talvez desenvolvido em contato com a realidade ibérica e a presença muçulmana, o pacífico e bondoso apóstolo Santiago assumiu muitas vezes, significativamente, $\mathrm{o}$ aspecto de Matamaros. ${ }^{34}$

Portanto, a Ordem Cluniacense ao penetrar e atuar na Península Ibérica fazia-o como resultado da própria dinâmica da sociedade feudoclerical e representando seu espírito e seus interesses. Mas o que levava à sua aceitação naquela região? Por muito tempo viu-se naquela penetração a obra pessoal de Sancho Maior de Navarra (1004-1035) que teria pretendido europeizar a Espanha, aproveitando-se do enfraquecimento de Córdoba, até entao um centro de gravitaçđo que exercera forte atraçao sobre a Cristandade ibérica. ${ }^{35}$ Mais recentemente, mostrou-se que aquela primeira penetraçao foi efêmera, e que a verdadeira "aliança castelhano-leonesa com Cluny" começou com Fernando I, pois Leao com suas pretensðes imperiais, mais do que a particularista Castela, respondia melhor às novas forças europeizantes antes mesmo de ter vínculos com o papado gregoriano. Tal aliança, contudo, foi reforçada por Afonso VI que precisava do apoio de Cluny para manter a soberania castelhano-leonesa frente às reivindicaçoes de Gregório VII, entao senhor feudal de Aragđo, para enfrentar o perigo almorávida e para superar a crise sucessória que se esboçava. Assim, entre 1054-1065 estaria o ponto crucial da história hispânica, pois entao começava a expansđo imperial castelhano-leonesa e nisso a aliança com Cluny reve 


\section{lou-se essencial..$^{36}$}

Podemos, de fato, em vários aspectos concordar com a interpretaçao de Bishko, cuja virtude principal foi ter compreendido o contexto político leonês e entrevisto mesmo uma "conexão espiritual" leonesa com a França como fatores básicos para a aliança dinástica com Cluny. Por outro lado, ao ver na política ibérica da década de 1068-1077 dois sistemas de aliança, cada um deles unindo uma monarquia hispânica a um centro eclesiástico estrangeiro (Aragão com Roma e Leão-Castela com Cluny), ele adota a discutível idéia que reduz a vinculação de Cluny com o Papado. Ademais, não considera devidamente seu caráter feudo-clerical, apesar de reconhecer sua perspectiva "pró-feudal", e nega assim o caráter belicista da ordem. Decorre disso que o interessante trabalho daquele estudioso não apreendeu convenientemente o significado de Cluny para a história ibérica.

Mais ainda, pela sua análise fica claro (de um ponto de vista cispirenaico) o porquê do momento da penetraçáo, resultado de circunstâncias da política dinástica ibérica, mas nđo por que a presença cluniacense se manteve mesmo após estar superado aquele conjunto de fatores. Para tanto, seria preciso considerar o caráter belicista e expansionista, isto é, feudo-clerical, de Cluny, o que o estudioso norte-americano nao aceita. Sem dúvida, a ideologia cluniacense revelava-se atraente para os monarcas ibéricos ao contribuir para reconquistar e repovoar os territórios dominados há muito pelos muçulmanos. Depois - é preciso cuidado para não superestimar o papel político de Cluny em detrimento da importância de seu significado espiritual em função do sentimento religioso comum aos dois lados dos Pirineus, os monarcas, como representantes da sociedade crista, precisavam promover uma reforma monástica da qual Cluny era a própria encarnação.

De fato, o monasticismo ibérico vira-se comprometido pelos avánços islamitas e pelos decorrentes problemas econômicos e políticos, razão pela qual iniciada a estabilizaçao da sociedade começou também a reconstruçáo monástica do século XI. ${ }^{37}$ Para essa obra Cluny também se afigurava como a melhor opção graças à fama de austeridade e santidade que a precedia. Em 1063, no próprio momento da penetração, Pedro Damiano, um dos mais importantes promotores da Reforma Gregoriana, perguntava: "o que mais poderei dizer do mosteiro de Cluny, seño que é um campo do Senhor, onde tantos monges vivem asceticamente como uma colheita de sementes celestes? O campo é lavrado com santas prédicas e nele se semeiam as sementes do verbo celestial. Nele se procede à colheita de grăos espirituais, para conservá-los nos celeiros de Deus". ${ }^{38}$

Passada a fase inicial de plantaçao das "sementes celestes" de Cluny em solo ibérico, chegou-se ao momento de consolidaçăo, em que os bons resultados alcançados anteriormente levaram de parte a parte a um estrei- 
tamento de laços. De um lado, o feudo-clericalismo transpirenaico beneficiava-se com a chegada de recursos econômicos e a saída de excedentes demográficos. De outro lado, as monarquias ibéricas recebiam os contingentes necessários à reconquista e ao repovoamento. Assim, a "Espanha havia se tornado, antes mesmo do período abacial de Săo Hugo, na terra prometida do monasticismo cluniacense". ${ }^{39}$ Em síntese, a presença de Cluny - e através dela da sociedade feudo-clerical - na Península Ibérica deveu-se a um encontro de interesses.

De fato, a aliança entre a dinastia castelhano-leonesa e Cluny foi selada pela concessão por parte de Fernando I de uma renda anual de mil dinares de ouro, quantia dobrada em 1077 por seu filho Afonso VI devido aos problemas do início de seu reinado e confirmaria em 1090 em virtude da questão sucessória. ${ }^{40} \mathrm{Em}$ função disso, poucos anos depois, Bernoldo de Constanza referia-se àquele rei como obedientarius do abade cluniacense. $^{41}$ Assim, graças ao ouro espanhol, a grande abadia da Borgonha podia em princípios do século XII dispender altas somas na compra de trigo e vinho, deixando em segundo plano a exploraçao direta de seu domínio. ${ }^{42}$ As conseqüências deste fato para a sociedade feudo-clerical são inegáveis, contribuindo para a passagem da economia dominial para a monetária, introduzindo ouro "na circulação monetária anêmica da França", beneficiando vários segmentos sociais da regiå, mas sobretudo os mercadores. ${ }^{43}$ Portanto, era a Península Ibérica sendo atraída para a órbita da sociedade feudo-clerical em virtude da dinâmica própria desta, que assim promovia seu crescimento econômico, mas também acelerava suas transformaçбes.

Outra forma, através da qual se consolidou aquela aliança entre as monarquias ibéricas e Cluny, foi uma política matrimonial que unia dinastias peninsulares com as casas de Borgonha e Aquitânia, ou seja, regiðes da órbita cluniacense. Limitando-nos aos séculos XI e XII (mas lembrando que tal política se estenderia pelos séculos seguintes, com grandes repercussð̋es históricas) e aos personagens mais importantes, recordemos apenas alguns exemplos. Do lado aragonês - fora portanto dos nossos limites geográficos, mas ligado a eles através dos constantes matrimonios entre as várias familias reais ibéricas - Ramiro I (1035-1063) casou-se em segundas núpcias com uma filha do duque de Aquitânia. Seu filho Sancho Ramirez (1063-1094) de um primeiro casamento teve o futuro Pedro I (1094-1104, que por sua vez casaria com uma filha de Guilherme VIII, conde de Poitiers e duque da Aquitânia) e de um novo matrimônio, com a filha do conde de Roucy, nasceram Afonso I Batalhador (1104-1134) e Ramiro II (1134-1137). Este por seu turno ligou-se a irma de Guilherme X de Poitiers, enquanto mais tarde uma filha de seu neto Afonso II (1162-1196) se casaria com o conde de Toulouse, Raimundo VI. 
No âmbito castelhano-leonês, Afonso VI (1072-1109) ligou-se matrimonialmente de início com Inês, filha de Guilherme VIII da Aquitânia, num segundo casamento com Constança, filha do duque de Borgonha e sobrinha do abade Hugo de Cluny, assim como foram francesas também suas terceira e quinta esposas. Duas de suas filhas casaram-se com sobrinhos de Constança: uma, Urraca, com Raimundo de Borgonha (daí nascendo o futuro Afonso VII) e outra, Teresa, com Henrique de Borgonha (de cuja união nasceu Afonso Henriques de Portugal). Uma terceira filha, Elvira, uniu-se a Raimundo IV de Saint-Gilles, conde de Toulouse, um dos herôis da Primeira Cruzada. Afonso VII (1126-1157), filho de borgonhess do lado paterno e neto pelo lado materno, por casamento tornou-se ainda genro da condessa da Provença e cunhado do conde de Foix. Seu filho Sancho III (1157-1158) casou-se com uma princesa navarra cuja mae era da familia condal de Perché; uma irma de Sancho casou-se com Luís VII de França. Assim, Afonso VIII (1158-1214), filho de seu antecessor e um dos mais importantes monarcas ibéricos do nosso período, tinha portanto do lado materno e paterno avós francesas. De seu casamento com Leonor de Inglaterra (filha de Henrique II e Leonor da Aquitânia) nasceu Branca de Castela, futura esposa de Luís VIII de França e assim mae de São Luís. ${ }^{44}$

Naturalmente, cada um destes personagens que passava a viver na península levava consigo toda uma entourage e abria caminho para a penetraçao de outros indivíduos provenientes de além-Pireneus. Para a prolífica nobreza francesa, as terras ibéricas representavam a possibilidade de obter feudos para seus secundogênitos. Eram comuns as esperanças de indivíduos como Roberto, o frísio, que por volta de 1070 pedia a seu pai: "de-me homens e barcos e irei criar para mim um Estado na Espanha". ${ }^{45}$ O sucesso completo de alguns - como Raimundo e Henrique de Borgonha, um recebendo a Galícia e tornando-se herdeiro do trono castelhano e outro ficando com Portugal, que seu filho transformaria em reino independente - funcionava como um forte chamariz. Mesmo sem repetir casos excepcionais como estes, muitos outros indivíduos puderam naquele "novo mundo" obter ao menos um pequeno senhorio ou uma paróquia, com mais sorte um condado ou uma diocese.

A quarta forma pela qual se manifestou a influência de Cluny na península foi a peregrinação a Compostela, utilizada como uma fonte a mais de prestígio e de recursos. Claro está que isso não significa que ela tenha sido uma criação artificial daquela ordem monástica para conscientemente explorar suas possibilidades econômicas e políticas. Contudo, não se pode negar o interesse de Cluny em incentivar aquela manifestação da sensibilidade religiosa da época, da qual ela própria era expressão e sinceramente pretendi desenvolver. Mas, afirmar que os reis hispânicos chamaram Cluny para or- 
ganizar as peregrinaçðes a Compostela, ${ }^{46}$ é tomar o efeito pela causa, é atribuir aos personagens envolvidos uma predeterminaçao que nada faz crer verossímel.

Por outro lado, salta à vista o empenho de Cluny, estando presente na península e cada vez mais envolvida nos seus destinos, em estimular a peregrinação e colher os seus frutos, espirituais e materiais. E significativo que em fins do século XI Cluny tenha levado diversas relíquias para a Espanha, procurando atender à natural tendência dos peregrinos em se sacralizarem ao máximo durante uma romaria. Daí, por exemplo, Oviedo ter se equipado nesse sentido, buscando aproveitar sua localizaçao na rota jacobea para levar os peregrinos a ali pararem. ${ }^{47} \mathrm{Com}$ o mesmo objetivo de incentivar as peregrinaçбes compostelanas, a tradicional data de 30 de dezembro para a festa do apóstolo foi transferida para 25 de julho, sem os inconvenientes que o inverno apresentava para a deslocação de grandes grupos e ainda adequando-a melhor ao calendário do rito romano. ${ }^{48}$

As duas grandes fontes sobre as peregrinaçбes compostelanas, escritas ambas por cluniacenses franceses, mostram-nos a estreita vinculaçao dos monges a elas. O Liber Sancti Jacobi ${ }^{49}$ estava preocupado em orientar o peregrino, em oferecer a ele uma antologia de peças litúrgicas, o relato dos principais milagres do santo, a historia da traslaçao de seu corpo para a península, a epopéia da peregrinaçđo de Carlos Magno e - claríssimo exemplo desta preocupação - um guia alertando-o dos perigos do caminho, aconselhando quanto aos locais de parada, revelando os santuários da rota. Portanto, obra simples, sem refinamentos literários, ingênua, escrita realmente para peregrinos - e mais do que isso, por peregrinos, já que constituída por elementos recolhidos da tradiçðo popular - mas que por isso mesmo sensibilizava, instigava. Por tudo isso, esta obra já foi considerada "uma espécie de livro oficial lançado pelos organizadores da peregrinação". 50

O cuidado com que o guia do Liber Sancti Jacobi fala dos vários corpos santos e relíquias existentes na rota, e que deveriam ser visitados pelos peregrinos, revela o interesse em canalizar o fluxo de romeiros para um certo sentido e para certos locais. E neles encontramos sobretudo a presença cluniacense. Dos quatro corpos santos que segundo o guia são irremovíveis, isto é, aprovam o sarcófago em que se encontram, todos estavam em locais de forte influência cluniacense: Santiago de Compostela, São Martinho de Tours, São Leonardo de Limonges e Saint Gilles. ${ }^{51}$ E significativo o longo elogio feito pelo guia às virtudes e aos poderes de Santo Eutrópio de Saintes, local entregue a Cluny em 1081 por Guilherme VIII da Aquitânia $:^{52}$ como ele fora recentemente integrado na verdadeira rede de santuários cluniacenses, o autor do guia deu àquele santo secundário um destaque que pudesse atrair peregrinos ao seu túmulo. 
Esta literatura propagandística era feita mesmo por mosteiros que. apesar de estarem fora da rota santiaguista, procuravam se beneficiar com a sua proximidade. Numa destas obras, pouco sutilmente, o autor procurava dar exemplos instrutivos que levassem os peregrinos a fazer oferendas generosas ao mosteiro. ${ }^{53}$ De fato, a elaboraçao dos miracula atendia nao só às necessidades espirituais dos fiéis, como ainda assegurava aos mosteiros uma "clientela crescente de peregrinos" e assim sua riqueza. ${ }^{54}$ Realmente, "um dos maiores tesouros com que se pode enriquecer os mosteiros é ter corpos santos e inúmeras relíquias que os estejam amparando e defendendo". ${ }^{55}$ Nao sem razão a concha de Santiago ornava o brasão dos abades de Cluny. ${ }^{56}$

A outra obra, Historia Compostellana, procurava exaltar a cidade e a Igreja do apóstolo, bem como as realizaçбes do arcebispo Diego Gelmirez, "muito perspicaz tanto para negócios eclesiásticos quanto seculares".57 Grande amigo de Cluny, ele devera ao abade Poncio a elevaçao de Compostela a sede metropolitana, autorizada pelo papa Calixto II, antigo monge, membro da familia condal de Borgonha, tio de Afonso VII e irmao de Raimundo da Galícia, eleito papa, aliás em Cluny, onde seu predecessor morrera como refugiado, devido ao conflito com o imperador.$^{58}$ Interessada também em atrair peregrinos, além de insistir sobre a dignidade e a apostolicidade da Igreja de Compostela, a obra chama atenção para as realizaçðes do santo, tendo o cuidado de acrescentar que ele "ajuda com inúmeros milagres todos os seus devotos de além e aquém-Pirineus". ${ }^{59}$

No plano prático, as realizaçбes de Gelmirez, verdadeiro cluniacense por afinidade, mostram sua perfeita consonância com o espŕrito e os objetivos da abadia: para facilitar o acesso à cidade melhorou trechos da rota $\mathrm{e}$ construiu albergues, ${ }^{60}$ reparou os portos galegos e organizou uma frota contra os muçulmanos; ${ }^{61}$ para suavizar a vida dos peregrinos construiu na cidade um aqueduto; ${ }^{62}$ regulamentou o mercado e fixou os preços dos principais produtos; ${ }^{63}$ de acordo com o expansionismo próprio ao Feudo-Clericalismo, procurou várias vezes estender os limites da jurisdição de sua sede, o que aconteceu sobretudo às expensas das de Braga e Mérida; ${ }^{64}$ como um grande senhor feudal conseguiu que todos os potentes da Galícia lhe prestassem homenagem ${ }^{65}$ e obteve mesmo de Afonso VI o direito, pouco comum na Espanha, de cunhar moeda. ${ }^{66}$ Coroando todo esse programa, Gelmirez planejou, como seu contemporâneo Suger, edificar uma catedral que fosse a glória do reino e de seu bispado.

$\mathrm{O}$ interesse cluniacense por Compostela e pelas peregrinaçðes é atestado ainda pelo envolvimento na política local e pela posse de inúmeros hospitais ao longo do camino francés. De fato, quando o casamento entre Urraca e Afonso I pôs em perigo os direitos hereditários de Afonso Raimundez, fi- 
tho do matrimônio de Urraca com Raimundo de Borgonha, Cluny claramente assumiu o papel de defensora do infante e assim dos interesses borgonheses. O arcebispo de Toledo, Bernardo de Salvetat, antigo monge da ordem, encabeçava a oposição, argumentando com o parentesco entre a rainha de Leão-Castela e o mọnarca de Aragão. $\mathrm{Na}$ Galícia, que Afonso VI havia atribuido como feudo ao seu neto, despontou um movimento objetivando torná-la um reino independente nas mãos de Afonso Raimundez, que foi mesmo coroado por Gelmirez na basilica de Compostela, em 1111. A confusa situação política que se seguiu - com inúmeras desavenças e reconciliaçơes entre Urraca e Afonso Batalhador, com as manobras do hábil e ambicioso Diego Gelmirez, com as intervençбes do conde de Portugal ${ }^{67}$ impediu a concretizaçao de algumas possíveis pretensøes de Cluny, que contudo viu satisfeita seu protegido tornar-se anos depois Imperador Hispaniae com o título de Afonso VII.

Quanto aos hospitais da rota compostelana, eles eram importantes por permitirem aos monges praticar a hospitalidade determinada por sua regra ${ }^{68}$ e beneficiar-se com a retribuiça dos peregrinos. Realmente, os hospitais eram vistos como "locais sagrados, casas de Deus para reconforto dos santos peregrinos, repouso dos indigentes, consolo dos doentes, salvaçao dos mortos, assistência aos vivos. Aqueles que edificaram essas santas casas ganharao, sem nenhuma dúvida, quem quer que eles sejam, o reino de Deus" ${ }^{69} \mathrm{Um}$ dos mosteiros cluniacenses ibéricos mais importantes, San Benito de Sahagún, em Leão, construiu, no tempo de Afonso IV, um hospital para peregrinos "no qual se gasta uma soma muito grande de dinheiro", distribuindo-se anualmente aos necessitados pelo menos 72.000 litros de trigo. ${ }^{70}$

Contudo, pode-se questionar o caráter desinteressado ou nao dessa hospitalidade, pois, pelo menos segundo os goliardos, cáusticos críticos da sociedade feudo-clerical, as casas monásticas não acolhiam "pobres, a quem os devotos monges deixam a porta". ${ }^{71}$ De qualquer forma, mesmo com despesas para o "repouso dos indigentes, consolo dos doentes", os hospitais contavam com a generosidade dos peregrinos ricos que por ali passavam e muitas vezes tornavam-se herdeiros de pessoas que ali morriam. Assim, entende-se a disputa de que certos hospitais eram objeto: em 1188 o prior de Villafranca queixava-se de um hospital proximo que "usurpava injustamente seus direitos sobre os peregrinos". ${ }^{72}$ Em 1277 os burgueses disputavam com a abadia a posse do hospital de Sahagún. ${ }^{73}$

Portanto, um conjunto de fatores espirituais (a religiosidade da peregrinaçao), institucionais (teocracia papal e reforma gregoriana) e materiais (doaçбes a mosteiros e hospitais) levara Cluny a se interessar pela sua implantaçao na Península Ibérica. A "verdadeira invasao cluniacense na península"74 foi acompanhada naturalmente por uma forte penetração de contin- 
gentes transpirenaicos, sobretudo franceses, fenômeno infelizmente não quantificável, mas claramente perceptível através de vários indícios. Tal é o caso, por exemplo, da existência de ruas e mesmo barrios francos em várias cidades na rota compostelana e nas regiøes reconquistadas; das inúmeras referências documentais a indivíduos de diferentes categorias sociais provenientes de além-Pirineus; da presença de usos e costumes, de técnicas comerciais e de elementos artísticos de origem não peninsular; de testemunhos topográficos e lingürsticos registrando a passagem daqueles indivíduos.

Em suma, a partir daquele encontro de interesses a que nos referimos e que acabamos de examinar, a sociedade feudo-clerical colocava através de Cluny vários encraves na península e deixava abertas muitas vias para dar continuidade à penetraçao. Muitos franceses passaram então a ocupar as principais dignidades eclesiásticas nas sés de Braga, Coimbra, Compostela, Osma, Segovia, Palencia, Sagunto, Valencia, Zamora e Salamanca. Bernardo de Cluny, nomeado arcebispo de Toledo, recebeu de Afonso VI a prerrogativa do supremo poder judicial sobre todos os eclesiásticos do reino, confirmada depois pelo papa cluniacense Urbano II, a quem fora encaminhado e recomendado pelo abade Hugo de Cluny, ${ }^{75}$ tornando-se assim, por quatro décadas, "o árbitro dos destinos da Espanha". ${ }^{76}$ Portanto, podemos estender para toda metade norte peninsular a observaça já antiga, mas que nao teve ressonância na historiografia - talvez esterilizada por outras observaçбes exaltadas e parciais do autor - de que "a história e as vicissitudes dos fueros da cidade de Sahagún provam, de maneira evidente, que os monges de Cluny se esforçavam por infiltrar nas aldeias de seu senhorio o espírito feudal que rechaçava nossos costumes e nosso direito." 77

Mas, como essa feudo-clericalizaçao peninsular se dava no momento em que se aceleravam as transformaçбes de sua matriz transpirenaica, a resultante ibérica do fenômeno ganhou feiçбes próprias. Ou seja, a montagem anacrônica do Feudo-Clericalismo ibérico - em fins do século XI, determinada em grande parte pelas condiçбes de Além-Pireneus - explica seu caráter dependente em relaçao àquelas regiøes. De fato, a penetraçao dos "francos", da qual Cluny foi um instrumento, respondia à necessidades da sociedade feudo-clerical clássica. Era uma verdadeira exportaçđo da crise transpirenaica, o que engendrava assim estruturas que mantiveram por séculos a Península Ibérica atrelada a interesses estrangeiros. 
NOTAS

${ }^{1}$ Este artigo foi extrafdo de um trabalho mais longo, apresentado como tese de Doutoramento na Universidade de São Paulo, e que será proximamente publicado pela Editora Hucitec com o título Origens medievais da dependência ibérica.

${ }^{2}$ Testamentum Willelmi Cognomento Pii, Arvenorum comitis et ducis Aquitanorum, De Constructione Cluniacensis Loci in Patrologia Latina. ed. Migne (abrev. PL) $133 \mathrm{col} .851$.

${ }^{3}$ VAlOUS, G. Cluny. Dictionnaire dHistoire et de Géographie Ecclesiastiques XIII, 140.

${ }^{4}$ Gregorii VII registrum ed. Ph. Jaffé Monumenta Gregoriana II, 174-176 apud GALLEGO BLANCO, E. Relaciones entre la Iglesia y el Estado en la Edad Media Madrid, Revista de Occidente, 1973, p.108-111.

5PINELL, J.M. Liturgia hispánica Diccionario de Historia Eclesiastica de España III, 1303-1320; CABROL, F. Mozarabe (La liturgie) Dictionnaire d'Archeologie Chrétienne et de Liturgie XII, 1 col. 390-491.

${ }^{6}$ GREGORIO VII Registrum I, 64 PL $148 \mathrm{col} .340$.

${ }^{7}$ SÃo HUGO Epistolae 11 PL $159 \mathrm{col} .939$.

${ }^{8}$ Chronicon Burgense ed. H. Florez España Sagrada Madrid, Antonio Marin, 1767 XXIII, 309; Annales Compostellani ibidem p.320-321.

${ }^{9}$ SANCHEZ ALBORNOZ, C. España, un enigma historico 2v. Barcelona, EDHASA, 8a. ed. 1981 I, 354-356. Contudo, apesar da 6́bvia influência do Papado na vida peninsular, não se pode falar de submissão da monarquia a ele, como já foi demonstrado para o século XIII: LINEHAN, P.A. The Spanish Church and the Papacy in the 13th century Cambridge, Cambridge University Press, 1971 p.101-127.

${ }^{10}$ DUBY, G. Guerriers et paysans Paris, Gallimard, 1973 p.62-69.

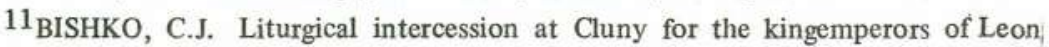
Studia Monastica 3, 1961 p.53-76.

12 Recueil des chartes de l'abbaye de Silos ed. M. Férotin Paris, Imprimerie Nationale-Ernest Leroux, 1897 nos 11, 12, 14, 16, 17 (doação de livros litúrgicos), 18, 19, 20,21 e 23.

${ }^{13}$ Idem, ibidem nọ $28,30,32,34,37,38,42,45,47,51,52,53,54,56,57,59$, $61,62,65,71$ e 73 .

${ }^{14}$ Cartulario del monasterio de Eslonza ed. V. Vignau Madrid, Imprenta de la Viuda de Hernando, 1885 nos $6,7,33,36,38,39,40,41,47,48,214,215,217,218$, 221 e 222. 
${ }^{15}$ Idem, ibidem nos $11,14,15,16,53,57,59,63,67,72,75,77,78,79,90,91$, $94,98,100,102,103,104,105,107,108,111,113,115,117,122,123$ e 224.

${ }^{16}$ Colección diplomática del monasterio de San Vicente de Oviedo (781-1200) ed. P. Floriano Llorente Oviedo, CSIC, 1968 nos 49, 52, 56, 59, 63, 64, 65, 69, 70, $74,75,83,90,92,97,102,103,108,117,118$ e 122.

${ }^{17}$ Idem, ibidem nos $125,134,136,137,138,154,156,158,174,175,176,178$, $180,185,186,198,201,203,204,205,206,211,213,214,216,218,222,224$, $226,227,228,233,235,238,241,243,244,245,247,248,252,254,255,258$, $259,260,261-268,271-275,277,279,286,293,294,298,300,302,304,306,307$, $309,312,314,315,319,321,324,336,337,342,345,347,348,349,353,357$, $359,364,366,367$ e 368 .

${ }^{18}$ Cartulario de Santo Toribio de Liébana ed. L.Sanchez Belda Madrid, Patronato Nacional de Archivos Históricos, 1948 nos 5, 7, 44, 45, 49, 51, 52, 53, 54, 56, 58, 60 , $61,67,70,71,75,77,81-86,90-95,104,105$ e 106 .

${ }^{19}$ Idem, ibidem nos $114,119,120,122,123,124,127-131,141,143,145,146$, $153,155,159,170,171,179,180,187,190,196,203,204,211$ e 241.

${ }^{20}$ Recueil des chartes de l'abbaye de Cluny ed. A. Bruel e A. Bernard 6v. Paris, Imprimerie Nationale, 1876-1903 VI, 4513, 4514.

${ }^{21}$ ADALBERON DE LAON Poeme au roi Robert ed. C. Carozzi Paris, Belles Lettres, 1979 v.156.

22 Idem, ibidem v.112, 148.

${ }^{23}$ DELARUELLE, E. L'Idée de croisade dans la littérature clunisienne du XI siècle et l'abbaye de Moissac Annales du Midi 75, 1963 p.419440 (reprod. L'idée de croisade au Moyen Age Turim, Bottega d'Erasmo, 1980, mesma paginação).

${ }^{24}$ DAVID, P. Gregoire VII, Cluny et Alphonse VI in Etudes historiques sur la Galice et le Portugal du VI au XII siècle Lisboa, Institut Français au Portugal - Instituto de Estudos Históricos, 1947 p.364, cf. tbem 369.

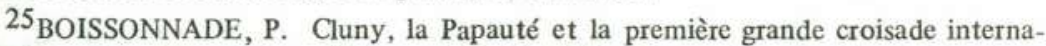
tionale contre les sarrasins d'Espagne (1064-1065) Revue des questions historiques 177,1932 p. $257-301$. 289.

${ }^{26}$ VAldeAvellano, L.G. Historia de Espana 2v. Madrid, Alianza, 1980 II,

27 DAVID, P. op.cit. p.373.

${ }^{28}$ VALOUS, G. op.cit. XIII, 54.

${ }^{29}$ RAUL GLABER Les cinq livres de seus histoires ed. M. Prou Paris, Picard, 1886 II, IX, 18; Liber Sancti Jacobi ed. A. Moralejo, C. Torres e J. Feo Santiago, CSIC, 1951 IV, VIII, 422; X, 427; XXI, 469-470; XXII, 478; XXIV, 487488; XXV, 491; XXVI, 493.

$3^{30}$ GRACIANO Decretum P.II, C.XXIII, Q.VIII, C.IX PL 187 col. 1248.

${ }^{31}$ Idem, ibidem, P.II, C.XXIII, Q.IV, C.XXXVIII col. 1198.

${ }^{32}$ La Chanson de Roland ed. J. Bédier Paris, L'edition d'Art, 1928, CXIV, 1489, 1504-1507; CXVI, 1536-1541; CXXI, 1610-1612; Liber Sancti Jacobi IV, XI, 429-430. 
33 Poema de mio Cid ed. I. Michael Madrid, Castalia, 2a ed. 1980, XCIV, 17021709; CXVI, $2370-2374$.

${ }^{34}$ Liber Sancti Jacobi II, XIX, 374-376; IV, 11, 409; Compilacion de los milagros de Santiago de Diego Rodriguez de Almela ed. J. Torres Murcia, CSIC-Universidad de Murcia, 1946 IV, 18; VII, 23; XIII, 32; XVI, 37.

35 MENENDEZ PIDAL, R. La España del Cid 2v. Madrid, Imprenta de la Viuda de Hernando, 1929 I, 118.

${ }^{36} 6_{\text {BISHKO, C.J. Fernando I y los origines de la alianza castellano-leonesa com }}$ Cluny Cuadernos de Historia de Espana 4748,1968 p.31-135 e 49-50, 1969 p.50116.

${ }^{37}$ PEREZ DE URBEL, J. Los monjes espanoles en la Edad Media 2v. Madrid, Instituto de Valencia de Don Juan, 1934 II, 398 ss.

38PEDRO DAMIANO Epistolae VI,4 PL $144 \mathrm{col} .374$.

${ }^{39}$ FLICHE, A. La reforme gregorienne et la reconquete chrétienne Paris, Bloud et Gay, 1940 p.435; cf. tbem VALOUS, G. op.cit. col. 51 .

40 Recueil de Cluny IV, 3509, 3638.

${ }^{41}$ BERNOLDO Chronicon Monumenta Germaniae Historica. Scriptores V, 457; expressão retomada por ANTONIO DE YEPES Cronica general de la orden de San Benito ed. J. Perez de Urbel 3v. Madrid, Atlas, 1953 I, LVIII, 273.

${ }^{42}$ Recueil de Cluny V, 4132, 4143.

${ }^{43}$ DUBY, G. Le budget de l'abbaye de Cluny entre 1080 et 1155 Annales. Economies. Sociétés. Civilisations 7, 1952, p.155-171 (reprod. em Hommes et structures du Moyen Age Paris, Mouton, 1973 p.61-82, especialmente p.68-70).

${ }^{44}$ BLEIBERG, G. (ed) Diccionario de Historia de España 3v. Madrid, Alianza, 1979; D'AMAT, R. et alii (dir) Dictionnaire de biographie française 14v. (em curso) Paris, Letouzey et Ané, 1932 ss; MICHAUD, J.F. (dir) Biographie universelle 45v. reed. Graz, Akademische DruckVerlagsanstalt, 1966-1970.

${ }^{45}$ Chronique de Lambert de Schaffenbourg apud DEFOURNEAUX, M. Les français en Espagne aux XI et XII siècles Paris, PUF, 1949 p.194.

${ }^{46}$ CAStro, A. La realidad historica de Espana Mexico, Porrua, 6a ed. 1975 p.144.

${ }^{47}$ GAIFFIER, B. Sante Ide de Boulogne et l'Espagne. A propos de reliques mariales Analecta Bollandiana 86, 1968 p.67-81. Mesmo se se aceitar que a rota compostelana retomava outras bem mais antigas, ño se pode deixar de reconhecer o papel de Cluny em melhor adequá-a à peregrinação, cobrindo-a de abrigos, refúgios e santuários: LAMBERT, E. Les routes des Pyrénées atlantiques et leur emploi au cours des ages Pirineos 7, 1951 p.362. Também para HIGOUNET, Ch. Un mapa de las relaciones monasticas transpirenaicas Pirineos 7,1951 p.543-552, a penetração cluniacense deu-se por caminhos tradicionais, anteriores.

48 Liber Sancti Jacobi III, III, 399-400.

${ }^{49}$ Quanto ds dúvidas que existiram num certo momento historiográfico, sobre a paternidade cluniacense do Liber Sancti Jacobi, elas absolutamente não procedem, como se verifica facilmente por uma análise interna do texto e pela simples observação do colofão da obra: "este códice foi escrito em vários locais, a saber, em Roma, em terras 
de Jerusalém, na Gália, na Itália, na Alemanha e na Frísia e principalmente em Cluny".

$50_{\mathrm{BEDIER}}$ J. Les légendes épiques. Recherches sur la formation des chansons de geste 4v. Paris, Edouard Champion, 3a ed. 1926-1929 III, 91.

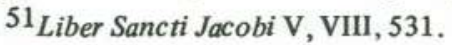

52 DEFOURNEAUX, M. op.cit. p.92.

53 GONZALO DE BERCEO Vida de Santo Domingo de Silos ed. T. Labarta de Chaves Madrid, Castalia, 1979 v.396a, 544b, 553bc, 580c, 587cd.

${ }^{54}$ HERRMANN-MASCARD, N. Les reliques des saints. Formation coutumiere d'un droit Paris, Klincksieck, 1975 p.410.

55 Cronica de la orden de San Benito op.cit. II, CXV, 237.

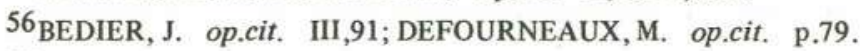

57 Historia Compostellana II,3 PL 170 col. 1034.

58 A Historia Compostellana trata longamente da amizade entre o bispo e o papa: II, $9,10,11$ col. 1043-1047.

${ }^{59}$ Idem, ibidem, II, 50 col. 1087.

${ }^{60}$ Idem, ibidem, I,30 col. 925.

${ }^{61}$ Idem, ibidem I,103 col. 998-999; II,75 col. 1132; III, 28 col. 1192-1193.

62 Idem, ibidem II,54 col. 1099-1100.

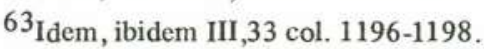

${ }^{64}$ Idem, ibidem II,18 col. 1056-1057, cf. CALIXTO II Epistolae et Privilegia 80-81 PL $163 \mathrm{col} .1170$. Idem, ibidem II,43 col $1081 \mathrm{cf}$. Epistolae et Privilegia 137 col. 1210-1211.

$65_{\text {Idem, ibidem II }, 29 \mathrm{col} .1067 .}$.

66 Idem, ibidem I,28 col. $922-923$.

67VALDEAVELLANO, L.G. op.cit. II, 393-423.

68 A Sancta Regula cap. 53 recomenda atenção especialmente aos pobres e peregrinos: San Benito, su vida y su regla ed. G.M. Colombas Madrid, BAC, 1954 p.584-595.

${ }^{69}$ Liber Sancti Jacobi V, IV, 508.

${ }^{70}$ Cronica de la orden de San Benito I, LIX, 292-293.

${ }^{71}$ Carmina Burana ed. C. Yarza e L. Moles Barcelona, Seix Barral, 2a ed. 1981 LX,3.

72 Recueil de Cluny V, 4209.

73 PEREZ DE URBEL, J. op.cit. II, 448. O valor econômico deste ramo de negócio explica que só em Portugal ao longo dos caminhos de peregrinação, para centros locais e estrangeiros, houvesse perto de 200 albergarias: OLIVEIRA MARQUES, A.H. A sociedade medieval portuguesa Lisboa, Sá da Costa, 2a ed. 1971 p.159.

${ }^{74}$ Idem, ibidem, II, 428, expressđo retomada por COLOMBAS, G.M. Benedictinos Diccionario de Historia Eclesiastica de España 1, 207 e que já tinha sido utilizada, em relaçã̃o ao "clero francês" por BALLESTEROS, A. Historia de España y su influencia en la Historia Universal 10v. Barcelona, Salvat, 1919-41 II, 154. 
75 RIVERA RECIO, J.F. El arzobispo de Toledo, don Bernardo de Cluny (10861124) Roma, Instituto Espaffol de Historia Eclesiastica, 1962 p.29-32.

76PEREZ DE URBEL, J. op.cit. II, 431.

${ }^{77}$ MUNOZ Y ROMERO, T. Refutación del opusculo Fueros Francos, Les communes françaises en Espagne et Portugal pendant le Moyen Age Madrid, Imprenta de la Revista de Legislación, 1867 p.31.

*Departamento de História

Universidade Estadual Paulista

Caixa Postal 211

14.400 - Franca-SP 